\title{
SOVIET EXPERIENCE AT VOSTOK AND PLANS FOR ANTARCTIC ASTRONOMY
}

\author{
V Burdyuzha \\ Astro Space Center, Moscow
}

The station Vostok is on the polar cap at an altitude of about $3500 \mathrm{~m}$. Vostok comprises a special complex for geophysical research together with accommodation and power generating facilities. Its location far inland at a high altitude provides a unique astroclimate. From 1958 to 1980 , the mean annual temperatures were $-55.3^{\circ} \mathrm{C}$ at Vostok, $-49.3^{\circ} \mathrm{C}$ at Amundsen-Scott (S. Pole), and $-11.3^{\circ} \mathrm{C}$ at Mirny (near the coast). Mirny recorded an average of 199 days/year with strong wind, Vostok only 3.2. The mean number of days/month with heavy cloud were 3.4 at Vostok, 4.0 at Amundsen-Scott, and 6.6 at Mirny. The number of days/year with little cloud: Vostok : 361, Mirny : 174.

Of the currently active scientific stations in Antarctica, Vostok has the best astronomical potential since the water vapour content on unclouded days is minimal $(\sim 0.17$ to $0.2 \mathrm{~mm}$ in the cold period, July to October). It is clear that submillimetric and millimetric observations can be made with the best efficiency in the region of Vostok.

Although the logistics at Vostok are not fully satisfactory now, sleigh tractor trains operate from the coast twice a year and there is an aircraft landing strip. In future, we shall give any help we can in organizing and building an international Antarctic observatory.

\section{FIRST INDIAN ASTRONOMICAL OBSERVATIONS IN ANTARCTICA}

Notes by editor from talk by G S D Babu, Indian Institute of Astrophysics

An Indian expedition to Antarctica (to the coastal base Maitri) in the 1989/' 90 summer made observations of the Sun to study the evolution and decay of supergranules, an experiment which benefited greatly from uninterrupted sessions of a few days. The instrument comprised a heliostat, a $1.2 \AA$ bandwidth blue filter, and a $10 \mathrm{~cm}$ aperture lens of about 3 metre focal length with recording on film. During January and February, one continuous period of more than 100 hours completely clear sky occurred, during which the transparency of the atmosphere was excellent. However, at times the seeing was a little poor. More than 2500 photographs were made at 10 minute intervals, as well as some at shorter intervals for studying the evolution of other solar features such as flares. 